\title{
The modal-epistemic argument for the existence of God is flawed
}

\author{
Stefan Wintein 1
}

Received: 15 May 2017/ Accepted: 20 March 2018/Published online: 27 March 2018

(C) The Author(s) 2018

\begin{abstract}
In a recent article, Emanuel Rutten has presented a novel argument for the existence of God, defined as a personal being that is the first cause of reality. An interesting feature of the argument, which caused quite a stir, is that it does not fall within any of the traditional categories of arguments for God's existence. Rutten calls his argument a modal-epistemic one, which reflects the fact that the first premise of his argument states that all possible truths are knowable. The main purpose of this article is a simple one: to point out that Rutten's modal-epistemic argument is flawed.
\end{abstract}

Keywords Modal-epistemic argument - God · Personal first cause · Rutten

\section{Introduction}

In a recent article (Rutten 2014), Emanuel Rutten presents a novel argument for the existence of God, defined as a personal being that is the first cause of reality. A first interesting feature of the argument is that it does not fall within any of the traditional categories of arguments for God's existence. In particular, Rutten's argument is neither an ontological, cosmological nor teleological argument. ${ }^{1}$ Rutten calls his argument a modal-epistemic one, which reflects the fact that the first premise of his

\footnotetext{
${ }^{1}$ See, for instance, Sobel (2004) for a concise overview of various ontological, cosmological and teleological arguments for God's existence. To be sure, further categories of arguments for God's existence exists such as moral arguments (cf. Adams 1987), but Rutten's argument does not fall within any of these further categories either.
}

Stefan Wintein

stefanwintein@gmail.com; stefanwintein@webklik.nl

1 Faculty of Philosophy, Erasmus University Rotterdam, Rotterdam, The Netherlands 
argument roughly states that all possibly true propositions are knowable. The second premise states that the proposition that God does not exist is not knowable. Then it validly follows from these two premises that God exists necessarily.

A second interesting feature of Rutten's argument is that it caused quite a stir, partly as a result of circumstances that Rutten (2012c: 7) describes, in his doctoral thesis, as follows.

Next, I would like to extend special thanks to Alexander Pruss who responded so enthusiastically on my new modal-epistemic argument for the existence of God, which resulted in its publication on Prosblogion which, in turn, led to it being mentioned on the website of the New York Times.

Ever since, Rutten's argument was and is widely discussed and hotly debated, on various philosophical websites as well as in more traditional media. However, the argument has, up till now, hardly received any attention in academic journals. ${ }^{2}$ Given the two interesting features of the argument that I mentioned above, I feel that such is regrettable.

In this article I scrutinize the modal-epistemic argument and point out that it is seriously flawed. In order to do so I first give, in "The modal-epistemic argument" section, a rigorous presentation of the modal-epistemic argument. "Worries about the first premise" section takes the second premise of the argument for granted and scrutinizes its first premise. I present counterexamples to the first premise and argue that the only way in which Rutten can save his premise from my counterexamples is by presupposing the conclusion of the modal-epistemic argument, which is dialectically inappropriate. In the section "Worries about the second premise", I argue that the second premise of the argument is false: given the notions of 'God' and 'knowability' that figure in the modal-epistemic argument, it turns out to be knowable that God does not exist. "The modal-epistemic core argument" section presents what I call the modal-epistemic core argument. This variant of the modalepistemic argument lays bare the core features of Rutten's argument and allows us see its rationale and flaws more clearly. Further, the core argument allows us to formulate a parody objection to the modal-epistemic argument. The parody argument shows that the standards of reasoning that Rutten appeals to, in order to conclude that it is necessarily true that God exists, also allow one to conclude that it is necessarily true that Saul Kripke exists. The final section, "Conclusion", concludes.

\footnotetext{
${ }^{2}$ An exception is Gijsbers (2012) which criticizes the modal-epistemic argument that appeared in Rutten's doctoral thesis (Rutten 2012c) and also in Rutten (2012a). See Rutten (2012b) for a reply to the critique of Gijsbers. In this article however, I am concerned with the modal-epistemic argument of Rutten (2014) which substantially improves his earlier argument as explained in footnote 3 and in Sect. 2.2.
} 


\section{The modal-epistemic argument}

\section{The simplified modal-epistemic argument}

Without further ado, let me present what Rutten (2014: 388) calls the simplified version of the modal-epistemic argument, ${ }^{3}$ which is the following valid argument with conclusion $C$ and premises $P_{1}$ and $P_{2}$.

\section{The simplified modal-epistemic argument (abridged version)}

$P_{1} \quad$ All possibly true propositions are knowable.

$P_{2}$ The proposition that God does not exist is not knowable.

$C$ The proposition that God exists is necessarily true.

I will explain the manner in which Rutten understands the crucial notions of his argument, God, knowledge and (im)possibility, in turn. I will unpack the content of these notions and use this unpacking to formulate the unabridged version of the above argument; by doing so I spell out how $P_{1}, P_{2}$ and $C$ must be understood.

As already explained, the notion of God that figures in the argument is that of a personal being that is the first cause of reality, i.e. a personal first cause. Thus, whereas in our colloquial language 'God' functions as a name, in the (simplified) modal-epistemic argument, 'God' is an abbreviation for the description 'a personal first cause'. In order to get a grip on the modal-epistemic argument, it will be instructive to make this explicit. In order to do so, let me introduce the predicates 'Personal being' and 'First cause of reality' so that the proposition that God exists, i.e. the proposition that there is a personal first cause, may be expressed as $\exists x(P(x) \wedge F(x))$.

Rutten (2014: 387) argues that the notion of a first cause entails that if a first cause exists, then it is unique. For if $x$ is a first cause, $x$ is the direct or originating cause of everything else besides $x$, whereas $x$ itself is not caused. Now suppose that there is more than one first cause and let $A$ and $B$ be two distinct first causes. Being a first cause, $A$ must have caused everything besides itself and so in particular $A$ must have caused $B$. But then $B$ is caused, which contradicts the assumption that $B$ was a first cause. Hence, if the simplified modal-epistemic argument is not only valid but also sound, it also establishes that the proposition that there is a unique personal first cause is necessarily true.

Now that we know what Rutten means with 'God', let us focus on the notion of knowledge that figures in $P_{1}$ and $P_{2}$. As Rutten (2014: 387) explains, this notion is such that 'knowledge requires near-certainty that has been produced in an epistemically proper way' and 'for a subject $S$ to know that a proposition $p$ is true, $S$ 's epistemic position must be such that $S$ cannot sincerely or genuinely doubt that $p$ is true'. More concrete and helpful is Rutten's description of the (only) four

\footnotetext{
3 Note: what is called the simplified modal-epistemic argument in Rutten (2014) is the actual modalepistemic argument as given in Rutten (2012a) and Rutten (2012c). Indeed, the modal-epistemic argument of Rutten (2014) is an improvement of the simplified modal-epistemic argument (which is identical to the modal-epistemic argument of Rutten (2012a; c)), as explained in "The modal-epistemic argument" section.
} 
possible knowledge sources than can ensure that a subject knows a proposition on his conception of knowledge.

...the ways to attain the required degree of certainty [for a subject to know a proposition] are exhausted by the following four options: (i) a proposition is deductively proven; (ii) a proposition is obviously true, i.e. intuitively selfevident; (iii) a proposition is grounded in indisputable experience; or (iv) a proposition is based on indisputable testimony. Rutten (2014: 387)

Rutten's argument (2014: 391) for premise $P_{2}$ proceeds by establishing that no one can know, on the basis of these four possible sources of knowledge, that God does not exist. Irrespective of the validity of this argument, to which we will return later, it should be noted that Rutten is claiming that it is unknowable that God does not exist according to his conception of knowledge. In order to make explicit that it is Rutten's stringent and specific conception of knowledge that figures in the (simplified) modal epistemic argument, I will refer to this conception as knowledge . $_{\text {. }}$ It will be instructive to illustrate the difference between our colloquial use of 'knowing that' on the one hand and 'knowing ${ }_{R}$ that' on the other in terms of proposition (1) below.

The population of New York is larger than that of Amsterdam.

In terms of our colloquial use of 'knowing that', many people do in fact know (1). However, no actual existing human being $\operatorname{knows}_{R}$ (1), as Rutten (2014: 397) rightly acknowledges. Nevertheless, Rutten argues that (1) is knowable ${ }_{R}$, which he does by asking us to consider 'an extra-terrestrial civilization whose members can observe an extensive geographical area on our planet with the same immediacy and resulting degree of certainty as we can observe our hands'. A member of this extra-terrestrial civilization can $\operatorname{know}_{R}(1)$ on the basis of indisputable observation, i.e. on the basis of knowledge source (iii). Hence, (1) is knowable . $_{\text {. }}$.

Finally, let us turn to the notion of (im)possibility. In order to do so in a convenient manner, we introduce the propositional operators ' $\diamond$ ', which reads as 'it is possible that', ' $\square$ ', which reads as 'it is necessary that' and ' $\mathrm{K}_{\mathrm{R}}$ ', which reads as 'some subject knows ${ }_{R}$ that'. The notational conventions that we just introduced allow us to express the simplified modal-epistemic argument in a concise manner: premise $P_{1}$ says that $\forall p\left(\diamond p \rightarrow \diamond \mathrm{K}_{\mathrm{R}} p\right)$, premise $P_{2}$ that $\neg \diamond \mathrm{K}_{\mathrm{R}} \neg \exists x(P(x) \wedge F(x))$ and the conclusion $C$ says that $\square \exists x(P(x) \wedge F(x))$. The operators $\square$ and $\diamond$ express metaphysical necessity and possibility respectively and have their meaning governed by the possible world semantics of the modal logic S5 (Rutten 2014: 388). This means that a proposition of form $\square \varphi$ is true just in case $\varphi$ is true in every possible world and that a proposition of form $\diamond \varphi$ is true just in case $\varphi$ is true in some possible world ${ }^{4}$. The possible world semantics allows us to spell out the content of $P_{1}, P_{2}$, and $C$ in the following precise way, which brings us to the unabridged version of the simplified modal-epistemic argument.

\section{The simplified modal-epistemic argument (unabridged version)}

\footnotetext{
${ }^{4}$ Throughout the paper, I will use 'possible world' as shorthand for 'metaphysically possible world'.
} 
$P_{1} \quad$ For every proposition $p$ that is true in some possible world $w$ there is some possible world $w^{\prime}$ (such that $p$ is true in $w^{\prime}$ and) such that there is a subject in $w^{\prime}$ that $\operatorname{knows}_{R}$ that $p$.

$P_{2}$ It is not the case that there is a possible world in which there is a subject that knows $_{R}$ that there is no personal first cause.

$C$ In every possible world there is a personal first cause.

The conclusion $C$ of the simplified modal-epistemic argument is thus that every possible world harbours a personal first cause. It further follows from the definition of a first cause that if $C$ is true, every possible world harbours a unique personal first cause. From this, it does not follow that every possible world harbours the same personal first cause. Indeed, it is compatible with the necessity of there being a unique personal first cause that the personal first cause in possible world $w$ has different properties than the personal first cause in possible world $w^{\prime}$. Unfortunately, this observation is somewhat obscured by Rutten's short and convenient presentation of his conclusion as 'the proposition that God exists is necessarily true'.

Before we proceed a clarificatory remark is in order. It may have struck the reader that $P_{1}, P_{2}$ and $C$ are used both for the constituents of the abridged and for the unabridged version of the simplified modal-epistemic argument. This is indeed the case and justified by the fact that the content of the abridged constituents is the same as the content of their unabridged counterparts: the abridged version of the argument is nothing but a convenient abbreviation of the unabridged version. I will sometimes exploit the notions of the abridged version, as doing so allows me to save some space. When I do so, let it be understood that the content of these notions is to be unpacked as in the unabridged version of the argument.

\section{The modal-epistemic argument}

Rutten argues that it is necessarily true that God exists. But he does not do so by invoking the simplified modal-epistemic argument, the reason being that premise $P_{1}$, as stated, is unacceptable. The genuine, unsimplified, modal-epistemic argument restricts the quantifier in $P_{1}$ to a subclass of propositions in order to avoid certain counterexamples to $P_{1}$. One type of such counterexamples may be illustrated by considering the following proposition.

There is extraterrestrial life and nobody nnows $_{R}$ it.

Intuitively, proposition (2) seems a clear instance of a proposition that is possibly true. In fact, our actual world might be such that it renders (2) true. But clearly, (2) is not knowable ${ }_{R}$. To see this, suppose that there is a world $w$ in which (2) is true and in which there is a subject $S$ that knows $_{R}$ that (2). As $S$ knows $_{R}$ that (2) and as knowledge $_{R}$ of a conjunction implies knowledge ${ }_{R}$ of both conjuncts, $S$ knows $_{R}$ that there is extraterrestrial life. Hence, there is somebody who $\operatorname{knows}_{R}$ that there is extraterrestrial life. But then the right conjunct of (2) is false, which renders (2) false, which contradicts the assumption that (2) is true in $w$. Hence there are no worlds in which it is both true and known $_{R}$ that (2): proposition (2) is not knowable $_{R}$. 
Proposition (2), and propositions like it, confront us with a dilemma. Either we must give up our judgement that (2) is a clear instance of a possible truth, or we must give up premise $P_{1}$. Rutten opts for the latter and proposes that propositions like (2) must be banned from the range of $P_{1}$ 's quantifier. He does so by invoking the distinction between first-order and second-order propositions. A first-order proposition, an example of which is 'there is extraterrestrial life', only states something about the world itself. A second-order proposition, an example of which is 'Jan knows $_{R}$ that there is extraterrestrial life' also states something about the propositional attitudes of a subject. ${ }^{5}$ Proposition (2) is a second-order proposition and Rutten proposes to modify $P_{1}$ by restricting its quantifier to first-order propositions. Indeed, whereas (2) is a counterexample to $P_{1}$, it is not a counterexample to premise $P_{1}^{\prime}$, where:

$P_{1}^{\prime} \quad$ All possibly true first-order propositions are knowable ${ }_{R}$.

As 'there is no personal first cause' is a first-order proposition, the conclusion that it is necessarily true that there is a personal first cause also follows from $P_{1}^{\prime}$ and $P_{2}$.

Be that as it may, there are counterexamples to premise $P_{1}^{\prime}$ which necessitate a further restriction of the range of its quantifier. To illustrate this, consider the following proposition.

\section{There are no conscious beings.}

Just as proposition (2), proposition (3) seems a clear instance of a proposition that is possibly true. And just like proposition (2), proposition (3) is a counterexample to $P_{1}$. For suppose that there is a world in which (3) is true and in which there is a subject that knows $_{R}$ that (3). This is impossible, as the truth of (3) implies that there are no conscious beings and hence there is no being that can $\operatorname{know}_{R}$ (3) or any proposition whatsoever. Thus there are no worlds in which (3) is both true and known $_{R}$ : proposition (3) is not knowable ${ }_{R}$. Unlike proposition (2) though, proposition (3) is a first-order proposition, and so it confronts us with a further dilemma: either we must give up our judgement that (3) is a clear instance of a possible truth, or we must give up premise $P_{1}^{\prime}$. Again, Rutten opts for the latter and proposes to ban propositions like (3) from the range of $P_{1}^{\prime}$ 's quantifier. Rutten remarks that no conscious being can believe (3) consistently as having any belief, and so in particular the belief that (3), commits one to the further belief that there are conscious beings, which contradicts one's initial belief. Rutten observes that the same remarks apply to propositions like 'nothing exists' or 'there only exists dead matter' and he calls proposition like these not consistently believable. Rutten takes it that these examples suffice to delineate the notion of a (not) consistently believable proposition and does not provide any further explication of that notion. However, it seems that on any reasonable explication of that notion, in order for a proposition to be consistently believable, it must be logically possible. ${ }^{6}$

\footnotetext{
5 There are also higher-order propositions. For instance, 'Jan knows ${ }_{R}$ that Piet knows ${ }_{R}$ that snow is white' is an example of a third-order proposition.

${ }^{6}$ I owe this insight to an anonymous referee.
} 
At any rate, Rutten proposes to restrict the range of the quantifier of $P_{1}^{\prime}$ to those first-order propositions that are consistently believable. Calling First-order Consistently believable propositions FoCons propositions, the further restriction of $P_{1}^{\prime}$ results in premise $P_{1}^{\prime \prime}$.

$P_{1}^{\prime \prime} \quad$ All possibly true FoCons propositions are knowable ${ }_{R}$.

Now everything is in place to formulate the modal-epistemic argument which, for sake of definiteness, we do in its unabridged form.

The modal-epistemic argument (unabridged version)

$P_{1}^{\prime \prime} \quad$ For every FoCons proposition $p$ that is true in some possible world $w$ there is some possible world $w^{\prime}$ (such that $p$ is true in $w^{\prime}$ and) such that there is a subject in $w^{\prime}$ that $\operatorname{knows}_{R}$ that $p$.

$P_{2} \quad$ It is not the case that there is a possible world in which there is a subject that knows $_{R}$ that there is no personal first cause.

$P_{3}$ The proposition that there is no personal first cause is a FoCons proposition.

$C$ In every possible world there is a personal first cause.

Now, given the plausible thought that all consistently believable propositions are logically possible, $P_{3}$ implies the logical possibility of the proposition that there is no personal first cause. Observe that this does not contradict $C$, according to which that same proposition is metaphysically impossible. ${ }^{7}$

With the full-blooded version of the modal-epistemic argument in place, it is now time to assess it. The argument is valid, no doubt. But is it also sound, i.e. are its premises true?

\section{Worries about the first premise}

\section{The blunt denial objection}

Consider the following proposition.

There is no personal first cause.

Just like propositions (2) and (3), proposition (4) seems to be a clear instance of a proposition that is at least possibly true. But as it follows from premise $P_{3}$ that (4) is a FoCons proposition, (4) must be knowable ${ }_{R}$ according to $P_{1}^{\prime \prime}$. However, premise $P_{2}$

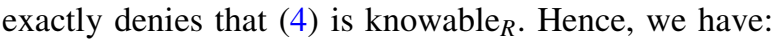

If (4) is possibly true then $P_{1}^{\prime \prime}, P_{2}$ or $P_{3}$ is false.

Note that (5) expresses the observation that if the conclusion of the modal-epistemic argument is false, then one of its premises must be false. Now this observation is not peculiar to the modal-epistemic argument, but applies to any valid argument whatsoever. Moore (1939) uses this observation to indirectly rebut the sceptic's

\footnotetext{
7 See also footnote 4 .
} 
argument: Moore argued that the conclusion of the sceptic's argument is false, as he knew he had hands, so that one of the premises of the sceptic's argument must be false. The strategy of indirectly rebutting an argument by attacking its conclusion rather than one of its premises is called the Moore-shift by Rowe (1979). ${ }^{8}$ What about a Moore-shift of the modal-epistemic argument? Can't we rebut the modalepistemic argument by pointing out that as (4) is possibly true, one of its premises must be false. Rutten (2014: 398) thinks that doing so is 'dialectically inappropriate' and that ...

...bluntly denying the conclusion of the argument, in order to point out that one of the premises must be false, isn't a good objection.

I agree with Rutten that inferring that an argument must have a false premise from a blunt, unmotivated denial of its conclusion is, in general, not a good objection to an argument: I agree that the Blunt Denial Objection is not a good one. That being said, a well-motivated, non-blunt, denial of its conclusion can very well constitute a legitimate objection to the modal-epistemic argument. However, in what follows, I will not argue for the falsity of the conclusion, but rather for the falsity of two of the premises of the modal-epistemic argument. In "The blunt denial objection" section I argue (assuming the truth of $P_{2}$ and $P_{3}$ ) that premise $P_{1}^{\prime \prime}$ is false. In section "A counterexample to premise $P_{1}^{\prime \prime \prime}$ " I argue that $P_{2}$ is false.

\section{A counterexample to premise $P_{1}^{\prime \prime}$}

For the purposes of this section, we take (Rutten's argument for) the truth of premise $P_{2}$ for granted and we (naturally) also accept $P_{3}$. Given these background assumptions we will now investigate whether or not $P_{1}^{\prime \prime}$ is true. In order to do so, consider the following proposition.

The only conscious beings are naturally evolved animals and humans.

Proposition (6) seems to be a clear instance of a proposition that is possibly true. In fact, a typical atheist and quite some scientists think that (6) is actually true. Moreover, (6) is both logically consistent and conceivable which, on a liberal notion of metaphysical possibility, are jointly sufficient for the (metaphysically) possible truth of (6). Although Rutten does not further pin down the notion of possibility that figures in the modal-epistemic argument, apart from specifying that it is metaphysical possibility which is at stake, Rutten is clearly committed to a liberal notion of metaphysical possibility. Indeed, Rutten (2014: 396-397) asks us to consider amongst others the following (metaphysically) possible worlds; a world where 'God exists, in which God is good and in which God knows his moral nature by indisputable experience in the form of introspection'; a world where 'God exists and decides not to create anything' and in which 'God exists and knows all logical and mathematical truths by direct intuition, including all Gödel propositions'. I do not have any qualms with a liberal notion of metaphysical possibility. However, given

\footnotetext{
8 Rowe (1979) is concerned with the argument from evil, a well-known argument for atheism. Rowe argues that the theist's best response to the argument from evil consist of a Moore-shift of that argument.
} 
such a liberal notion, (6) must be regarded as possibly true. Let us now turn to the knowability $_{R}$ of (6).

Rutten's argument (2014: 391) for premise $P_{2}$, i.e. for the unknowability ${ }_{R}$ of (4), proceeds by establishing that no subject can know, on the basis of knowledge sources (i)-(iv), that there is no personal first cause. As already indicated above, we accept (at least in this section) Rutten's argument for $P_{2}$. His argument for the unknowability $_{R}$ of (4), however, readily carries over into an argument for the unknowability $_{R}$ of (6). First, Rutten claims that to $\mathrm{know}_{R}$ that there is no personal first cause via knowledge source (i) comes down to showing that the notion of a personal first cause is contradictory. Such is not the case and so one cannot know (4) on the basis of knowledge source (i). But then, as the notion of a conscious being that is neither an animal nor a human is also non-contradictory, one cannot come to know $_{R}$ proposition (6) on the basis of knowledge source (i). Second, as (6) is neither self-evident nor obviously true, one cannot come to $\mathrm{know}_{R}(6)$ on the basis of knowledge source (ii). Third, as one can never experience 'that everything that exists has indeed been experienced' one cannot conclude on the basis of experience, whatever its contents are, that there are neither non-human nor non-animal conscious beings: one cannot come to $\mathrm{know}_{R}(6)$ on the basis of source (iii). The fourth and final knowledge source (iv) is that of indisputable testimony. From the truth of (6), it follows that every potential testifier is an animal or human being. But no (animal or) human being, whatever her reliability, is able to put another (animal or) human being in an epistemic position in which he can no longer 'sincerely or genuinely doubt that (6) is true'. Hence, (6) is a FoCons proposition which is unknowable . $_{\text {. }}$

Another and more informative way to see that (6) must be unknowable $_{R}$ is as follows. Observe that (6) implies $^{9}$ (4): if the only conscious beings are naturally evolved animals and human beings (with the first conscious beings coming into existence after the Hadean Eon) there is no personal first cause of reality. To establish that (6) is unknowable ${ }_{R}$, observe that any subject that knows $_{R}(6)$ is also in the position to nnow $_{R}(4)$ on the basis of Modus Ponens and the fact that (6) implies (4). Hence if (6) is knowable ${ }_{R}$, so is (4). But as premise $P_{2}$-whose truth we take for granted in this section-exactly tells us that (4) is unknowable , $_{R}$ it follows by contraposition that (6) must also be unknowable ${ }_{R}$. Indeed, it is the mere fact that (6) implies (4) that allows us to conclude that (6) is unknowable ${ }_{R}$ : any proposition that implies (4) must be unknowable ${ }_{R}$. Calling propositions that imply (4) God-deniers, we may record this observation as the following fact.

GDU If $P_{2}$ is true then any God-denier is unknowable ${ }_{R}$.

Now in contrast to God-denier (4), to accept God-denier (6) as possibly true is not to bluntly deny the conclusion $C$ of the modal-epistemic argument. For one thing, (6) does not mention the notion of a personal first cause at all, but involves more mundane notions such as 'animal', 'human' and 'conscious being'. Then again, as (6) implies (4), accepting (6) as possibly true involves an implicit denial of $C$. So

\footnotetext{
9 If one doubts whether (6) implies (4) simply add 'and the first conscious beings came into existence after the Hadean Eon' to the content of (6).
} 
then, can Rutten save his modal-epistemic argument by declaring (6) to be an illegitimate counterexample to $P_{1}^{\prime \prime}$ because taking it as such involves an implicit denial of $C$ ?

\section{Appealing to implicit denials is question-begging}

Here are two reasons as to why Rutten cannot rule out (6) as an illegitimate counterexample to $P_{1}^{\prime \prime}$ by appealing to the fact that (6) involves an implicit denial of C.

First, ruling out (6) as an illegitimate counterexample to $P_{1}^{\prime \prime}$ because it involves an implicit denial of $C$ is simply question-begging. Remember that I am not bluntly denying that 'there is a personal first cause' is necessarily true and that therefore one of the premises of the modal-epistemic argument must be false: I am not raising the Blunt Denial Objection. Rather, I charitably accept premises $P_{2}$ and $P_{3}$ as unproblematic truths and I am assessing whether I should also accept $P_{1}^{\prime \prime}$. Now (6) is a FoCons proposition that is a clear example of a proposition that, given Rutten's notion of metaphysical possibility, must be regarded as possibly true. But it is not knowable $_{R}$. Hence (6) is a counterexample to $P_{1}^{\prime \prime}$. To say that it is an illegitimate counterexample because taking it as such implies that $C$ is false is question-begging, as we are invited to accept $C$ on the basis of $P_{1}^{\prime \prime}$ and the other two premises.

Second, consider again proposition (3), i.e. the proposition that there are no conscious beings. If there are no conscious beings, then there is no personal first cause. Hence proposition (3) also implies (4) and so accepting (3) as possibly true also involves an implicit denial of $C$. And so Rutten could also have saved $P_{1}^{\prime}$ from counterexample (3) by appealing to an implicit denial of $C$ : he could have said that (3) is not possibly true as taking it as such would come down to an implicit denial of $C$. He could have, but he did not. Rather, he chose to invoke the notion of a consistently believable proposition to save $P_{1}^{\prime}$ from (3). Now if the only motivation for the restriction to consistently believable proposition were the mere fact that it saves $P_{1}^{\prime}$ from counterexamples, the restriction could rightfully be called ad hoc. However, Rutten (2014: 392) explains that such is not the case as 'belief is, after all, a condition on knowledge, so if a proposition cannot be believed consistently in the first place, it cannot figure in claims about knowability'. Let us accept that the restriction to consistently believable propositions is not ad hoc for the reasons that Rutten states above: a proposition that is not consistently believable is definitely not knowable $_{R}$ and so propositions such as (3) should not be allowed to spoil the conceptual relation between possible truth and knowability $_{R}$ that is echoed in the first premise. Fair enough. But is (3) possibly true? Clearly, Rutten must think that it is not: for if (3) is possibly true, there must be a world in which there is no personal first cause, which contradicts Rutten's conclusion that every possible world harbours a personal first case. Although Rutten may very well think that (3) can't be possibly true on the basis of $C$ he can, of course, not appeal to this impossibility when arguing for the truth of his premises, as he clearly realizes:

If classical theists are right that God's existence is necessary, then 'There are no conscious beings' is a necessary falsehood. But in the present context, of 
course, classical theism cannot be presupposed. And as I said before, necessary existence is not part of my conception of God. Rutten (2014: 392)

Indeed, when developing an argument whose purported conclusion is that it necessarily true that a personal first cause exists, one cannot presuppose (a position from which it follows) that it is necessarily true that such a cause exists. Moreover, in such a context one cannot argue that (3) is not possibly true as such follows from a presupposition that it is necessarily true that God exists. Hence, Rutten rightly acknowledges that if his argument is to have any bite at all, he cannot rule out (3) as possibly true in virtue of a position which presupposes the conclusion of his argument. Classical theism is such a position, but another such position is the view that all God-deniers are necessarily false. Hence, the implicit denial move is not acceptable by Rutten's own standards: just as it is inappropriate to rule out (3) as possibly true in virtue of classical theism, so it is inappropriate to rule out (6) because it involves an implicit denial of $C$.

To sum up, as proposition (6) is unknowable ${ }_{R}$, premise $P_{1}^{\prime \prime}$ can only be true when (6) is necessarily false. And so in order to soundly conclude $C$ from $P_{1}^{\prime \prime}$ and the other premises, one must argue that (6) is necessarily false. To say that (6) is necessarily false as it involves an implicit denial of $C$ or to simply presuppose that (6) is necessarily false is question-begging, which also seems to be recognized by Rutten himself, given his remarks on (3).

In this section we investigated premise $P_{1}^{\prime \prime}$ and took it for granted that premise $P_{2}$ is true. In the next section, we will investigate premise $P_{2}$ and argue that it is false.

\section{Worries about the second premise}

\section{A parity objection to the modal epistemic argument}

Before we present our qualms with premise $P_{2}$, we will first present an objection to the modal-epistemic argument that Rutten discusses and dismisses in his paper. Doing so is instructive, as Rutten's rebuttal of this so-called parity objection paves the way for our argument against $P_{2}$.

One of the potential objections to his argument that Rutten discusses and dismisses in his paper is the following parity objection: just as it is impossible to know $_{R}$ that there is no personal first cause, it is also impossible to know ${ }_{R}$ that there is a personal first cause. Together with $P_{1}^{\prime \prime}$ and $P_{3}$, the unknowability ${ }_{R}$ of 'there is a personal first cause' entails that it is necessarily false that God does exist. Hence, the modal-epistemic argument is flawed. Or so the parity objection goes.

Rutten shows that the parity objection is untenable by arguing that it is possible to $\mathrm{know}_{R}$ that there is a personal first cause. He does so along the following lines. There is a possible world in which there is a (unique) personal first cause, called God, and in which God knows ${ }_{R}$ that he is the personal first cause. Rutten (2014: 395) suggests that God can $\mathrm{know}_{R}$ this either on the basis of 'indisputable inner experience of his own nature', i.e. on the basis of knowledge source (iii), or that it may be that 'God knows that he is God by direct intuition', i.e. by knowledge source 
(ii). Further, Rutten suggest that as God is the personal first cause, everything that is originates with God, and so God is in 'a maximally ideal cognitive situation' and so 'plausibly also knows himself to be in that situation'. With respect to this last suggestion, Rutten does not explicitly mention the knowledge source that gives rise to God's knowing ${ }_{R}$ that he is the personal first cause. However, it seems plausible that it must originate in source (iii): God's indisputable experience of creating the world.

Thus, Rutten sketches three possible ways in which a personal first cause can know $_{R}$ that he is the personal first cause: the proposition that God exists is, pace the parity objection, knowable $_{R}$. I will not dispute the legitimacy of Rutten's rebuttal of the parity objection. I take it for granted that the notions of metaphysical possibility and knowledge $e_{R}$ allow Rutten to establish that the proposition that there is a

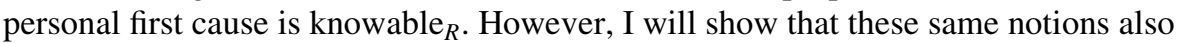
allow us to establish that the proposition that there is no personal first cause is knowable $_{R}$, and hence show that premise $P_{2}$ is false.

\section{A counterexample to premise $P_{2}$}

In order to show that premise $P_{2}$ is false, consider a possible world in which there are (exactly) two personal uncaused causes, which we call $A$ and $B$. These uncaused causes are co-creators of the world in the sense that everything that there is, except for $A$ and $B$, (which are uncaused and so not created) is jointly created by $A$ and $B$. The sketched situation may be conveniently summarized by the following proposition.

There are exactly 2 personal uncaused causes that co-created the world.

The situation involving $A$ and $B$ that we sketched above gives rise to a possible world in which (7) is true. Indeed, given the notion of metaphysical im(possibility) to which Rutten appeals, (7) must be considered as a possible truth. Or if not, Rutten would have to explain why (7) is necessarily false whereas he regards the following proposition as possibly (in fact necessarily) true.

There is exactly 1 personal uncaused cause that created the world.

As we explained in "The modal-epistemic argument" section, it follows from the notion of a first cause that such a cause is an uncaused creator of the world (apart from itself) and that if such a cause exists, it is unique. Hence, (8) is a mere restatement of the proposition that there is a personal first cause and Rutten effectively argues that it is possible to $\mathrm{know}_{R}(8)$. The central tenet in Rutten's argument for the knowability ${ }_{R}$ of (8), is that it is possible for the (unique) personal first cause to know $_{R}$ its own nature in at least three ways. But then, it seems naturally that there is also a possible world in which (7) is true and in which the two personal uncaused causes that co-created the world (both) know $_{R}$ that (7). For instance, if $A$ and $B$ co-created the world, they can plausibly know $_{R}$ that they did on the basis of source (iii): their indisputable experience of creating the world. And to the extent that it is plausible that a personal first cause can $\operatorname{know}_{R}$ that he is a 
personal first cause on the basis of direct intuition, it is also plausible that a personal co-creator of the world can $\mathrm{know}_{R}$ that he is such a co-creator on the basis of direct intuition. Finally, to the extent that it is plausible that a personal first cause can know $_{R}$ that he is a personal first cause on the basis of an indisputable inner experience of his own nature, it is also plausible that a personal co-creator of the world can know $_{R}$ that he is such a co-creator on the basis of an indisputable inner experience of his own nature. Indeed, to the extent that is plausible that a personal first cause can know $_{R}(8)$, it is also plausible that a personal co-creator of the world, such as $A$, can know ${ }_{R}$ (7). But, as (7) implies that (8) is false, when $A$ knows $_{R}$ (7) he is also in a position to $\mathrm{know}_{R}$ that (8) is false. And hence there is a subject, namely $A$, who can know $_{R}$ that there is no personal first cause. Hence premise $P_{2}$ is false.

Or is it? It will be instructive to consider (and dismiss) a potential rejoinder of my argument for the falsity of $P_{2}$. One might consider arguing that " $A$ and $B$ taken together" constitute a personal first cause so that (7) does not, in contrast to what I claim, imply the falsity of (8). However, this argument is bound to fail. Granted, if the entity denoted by " $A$ and $B$ taken together", i.e. the fusion or mereological sum of $A$ and $B$ exists, that fusion definitely counts as a first cause. Further, according to mereological universalim (cf. Schaffer 2017), the fusion of any two objects exists and so in particular the fusion of $A$ and $B$. However, whereas the existence of the fusion of $A$ and $B$ guarantees the existence of a first cause, it does not guarantee the existence of a personal first cause. Rutten (2014: 386) explains that a personal being is a 'somebody not something [and] is therefore capable of knowledge (and thus of belief, reason, intuition, and experience)'. It seems outrageous to claim that these properties, ascribed to personal beings, carry over to the fusion of such beings. At any rate, to claim that these properties do carry over needs a sustained metaphysical argument that is not to be found in current mereological theories.

This concludes our assessment proper of the status of modal-epistemic argument, which we have shown to be flawed. In the next section we will present what we call the modal-epistemic core argument. This variant of the modal-epistemic argument lays bare the core features of Rutten's argument and allows us to see its rationale and flaws more clearly.

\section{The modal-epistemic core argument}

In order to argue that certain alleged counterexamples to $P_{1}^{\prime \prime}$ are just that, alleged counterexamples, Rutten appeals to God as a possible knower $_{R}$. For instance, when confronted with the alleged unknowability ${ }_{R}$ of proposition (9),

There is a personal first cause,

Rutten points out that it is possible that there is a personal first cause who $\mathrm{knows}_{R}$ (9), as we explained in the previous section. Another example of a proposition whose knowability ${ }_{R}$ is established by appealing to God is (10). 
A Spaghetti monster does not exist.

In order to argue that (10) is knowable ${ }_{R}$, Rutten (2014: 396) points out that there is a possible world in which there is a personal first cause that decides to create nothing. In this world, the personal first cause $\operatorname{knows}_{R}(10)$ and so (10) does not give rise to a counterexample to $P_{1}^{\prime \prime}$. Finally, in order to establish that so-called Gödel propositions, i.e. propositions that are possibly true but that are not provable in any proper mathematical axiom system, are knowable $_{R}$, Rutten (2014: 397) asks us to consider 'a possible world in which God exists and in which God's immediate rational intuition about logical and mathematical propositions is perfect. In this world, God knows all logical and mathematical truths by direct intuition, including all Gödel propositions.'

Now Rutten's appeal to God to ensure the knowability ${ }_{R}$ of propositions such as (9), (10) or Gödel propositions may not be necessary: perhaps such propositions can also be known $_{R}$ by other subjects. Then again, Rutten's appeal to God to ensure the knowability $_{R}$ of such propositions trivially reveals that he takes it to be possible that a personal first cause knows $_{R}$ these propositions. In fact, it seems that a great many propositions are knowable ${ }_{R}$ by a personal first cause. More precisely, it seems that Rutten is committed to:

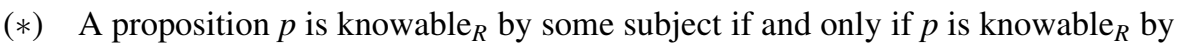
a personal first cause.

As any personal first cause is a subject, the right-to-left direction of $(*)$ is trivially true. Rutten, however, is also committed to the left-to-right direction of $(*)$, which follows from his use of the notion of a personal first cause, in particular from how he uses this notion to argue for the knowability ${ }_{R}$ of propositions such as (9), (10) or Gödel propositions. To be sure, I am not claiming that $(*)$ is true, but only that Rutten is committed to $(*)$. In fact, in the previous section I presented a counterexample to $(*)$. There I argued that (4), i.e. the proposition that there is no personal first cause, is knowable ${ }_{R}$ by a personal uncaused cause that co-created the world. Hence (4) is knowable ky $_{R}$ by subject but clearly not knowable $\mathrm{k}_{R}$ by a personal first cause. Rutten, of course, cannot accept (4) as a counterexample to (*) as doing so comes down to accepting that $P_{2}$ is false. More generally, it follows from GDU that if $P_{2}$ is true, every God-denier is unknowable $R_{R}$ and hence Rutten cannot accept any God-denier as a counterexample to $(*)$. As Rutten's use of the notions of knowability $_{R}$ and personal first cause do not seem to allow for any counterexample to $(*)$ other than a God-denier, the conclusion that Rutten is committed to $(*)$ is warranted.

Now it immediately follows from $(*)$ that premises $P_{1}^{\prime \prime}$ and $P_{2}$ are equivalent to $P_{1}^{*}$ and $P_{2}^{*}$ respectively, where:

$P_{1}^{*} \quad$ All possibly true FoCons propositions are knowable ${ }_{R}$ by a personal first cause.

$P_{2}^{*} \quad$ The proposition that there is no personal first cause is not knowable ${ }_{R}$ by a personal first cause.

To be sure, $P_{1}^{*}$ does not say that there is a personal first cause that is omniscient. What it does say, in its unabridged form, is that for any proposition $p$ that is true in 
some possible world $w$, there is some world $w^{\prime}$ in which there is a personal first cause who knows ${ }_{R}$ that $p$. Premise $P_{2}^{*}$ is a tautology whose truth cannot be doubted.

The (valid) argument with premises $P_{1}^{*}, P_{2}^{*}$ and $P_{3}$ and conclusion $C$ we will call the (modal-epistemic) core argument. A nice feature of the core argument is that it clearly lays bare the essential flaw of the modal-epistemic argument, as we will explain below.

The modal-epistemic argument exploits the notion of knowability $_{R}$, which is a very demanding conception of knowledge, according to which human beings cannot even know $_{R}$ mundane truths such as (1). However, the modal-epistemic argument also exploits a very liberal notion of metaphysical possibility (cf. "A counterexample to premise $P_{1}^{\prime \prime}$ " section), ensuring that whereas humans can hardly know kny $_{R}$ possible truth, a vast amount of possible truths is nevertheless knowable ${ }_{R}$ by some metaphysically possible subject. A central and dual role is reserved for those metaphysically possible subjects that satisfy the description 'a personal first cause'. On the one hand, a personal first cause is considered to be a very strong knower $_{R}$, as witnessed by Rutten's commitment to $(*)$. As such, the notion of a personal first cause seems to be tailor-made to ensure the truth of $P_{1}^{\prime \prime}$. On the other hand, it is very hard to $\mathrm{know}_{R}$ something (for subjects that do not satisfy the description 'a personal first cause') about a personal first cause, as witnessed by Rutten's discussion of propositions like (9) and premise $P_{2}$. As such, the notion of a personal first cause seems to be tailor-made to ensure the truth of $P_{2}$.

The central and dual role of the notion of a personal first cause is thus supposed to ensure the truth of both $P_{1}^{\prime \prime}$ and $P_{2}$, and this core feature of the modal-epistemic argument is vividly illustrated by the core argument. First, it is trivially true that no proposition that implies that there is no personal first cause is knowable $_{R}$ by a personal first cause. And so, in contrast to $P_{1}^{\prime \prime}$, premise $P_{1}^{*}$ wears its presuppositionthat all God-deniers are necessarily false-on its sleeves. As such, the core argument thus allows us to see more clearly the main flaw of the modal-epistemic argument. Second, given the presupposition that all God-deniers are necessarily false, premise $P_{2}$ is effectively a tautology as no necessarily false proposition, and so in particular not God-denier (4), is knowable $_{R}$. Although the formulation of premise $P_{2}$ hides this tautological character, this character is clearly revealed by $P_{2}^{*}$.

Indeed, the basic structure of the modal-epistemic argument is the same as that of the core-argument; the core-argument simply reveals that the modal-epistemic argument presupposes its conclusion in a more explicit way. To accept $C$ on the basis of the modal-epistemic argument is just as reasonable as to accept this conclusion on the basis of the core argument.

Let me finish this section by presenting a parody objection to the core argument and so by extension to the modal-epistemic argument. The first premise of the parody argument does not involve a restriction to FoCon propositions but rather to FolKri propositions. A FolKri proposition is any proposition that is expressible by a sentence of a first-order language with identity, without any predicate or function symbols and with a single constant symbol $\kappa$ that refers to Saul Kripke. Thus the proposition that everything is self-identical, which can be expressed as ' $\forall x(x=x)$ ' is a true FolKri proposition. The proposition that not everything is identical to Saul 
Kripke, ' $\neg \forall x(x=\kappa)$ ' is another true FolKri proposition. These FolKri propositions are not only (possibly) true but also knowable ${ }_{R}$ by Saul Kripke (who knows his logic). In fact, it seems rather plausible that every possibly true FolKri proposition is knowable $_{R}$ by Saul Kripke, which is the first premise of the modal-epistemic argument for Kripke's necessary existence.

The modal-epistemic argument for Kripke's necessary existence.

$K_{1} \quad$ All possibly true FolKri propositions are knowable ${ }_{R}$ by Saul Kripke.

$K_{2}$ The proposition that Saul Kripke does not exist is not knowable $R_{R}$ by Saul Kripke.

$K_{3}$ The proposition that Saul Kripke does not exist is a FolKri proposition.

$C_{K}$ The proposition that Saul Kripke exists is necessarily true.

I believe that Saul Kripke exists. But I do not believe that he necessarily does so. My beliefs about Kripke are unaffected by the modal-epistemic argument for his necessary existence. Similarly, my beliefs about the (necessary) existence of God are unaffected by Rutten's modal-epistemic argument.

\section{Conclusion}

I argued that Rutten's modal-epistemic argument is flawed: attempts to argue for its first premise are either question-begging or render the modal-epistemic argument redundant and its second premise is false. As an afterthought, I presented the modalepistemic core argument, a variant of the modal-epistemic argument which clearly reveals the rationale and flaws of Rutten's argument.

Open Access This article is distributed under the terms of the Creative Commons Attribution 4.0 International License (http://creativecommons.org/licenses/by/4.0/), which permits unrestricted use, distribution, and reproduction in any medium, provided you give appropriate credit to the original author(s) and the source, provide a link to the Creative Commons license, and indicate if changes were made.

\section{References}

Adams, R. (1987). Moral arguments for theism. The virtue of faith and other essays in philosophical theology (pp. 144-163). New York: Oxford University Press.

Gijsbers, V. (2012). Wat is er mis met Ruttens modaal-epistemicsche argument? Radix, $38,4$.

Moore, G. E. (1939). Proof of an external world. Proceedings of the British Academy, 25, 273-300.

Rowe, W. L. (1979). The problem of evil and some varieties of atheism. American Philosophical Quarterly, 16(4), 335-341.

Rutten, E. (2012a). Een modaal-epistemich argument voor het bestaan van God. Radix, 38(3), 206-215.

Rutten, E. (2012b). Repliek op Gijsbers. Radix, 38, 4.

Rutten, E. (2012c). A critical assessment of contemporary cosmological arguments: Towards a renewed case for theism. ISBN 9789081960809 , Vrije Universiteit Amsterdam.

Rutten, E. (2014). A modal-epistemic argument for the existence of God. Faith and Philosophy, 31(4), $386-400$.

Schaffer, J. (2017). The Ground between the gaps. Philosophers' Imprint, 17(11), 1-26.

Sobel, J. H. (2004). Logic and theism: Arguments for and against beliefs in god. Cambridge: Cambridge University Press. 